\title{
Impact of COVID-19 on the Egyptian economy: Economic sectors, jobs, and households
}

\author{
Clemens Breisinger, Mariam Raouf, Manfred Wiebelt, Ahmed Kamaly, and \\ Mouchera Karara
}

The COVID-19 crisis may lead to a 1.1 percent decline in Egypt's GDP during the 4th quarter (April to June) of the 2019/20 fiscal year, compared to the same quarter in 2018/19. Without the Government of Egypt's COVID-19 emergency response package, GDP in Q4 may have declined by 8.7 percent. Taking the emergency response package into account, we estimate an annual growth rate of 3.8 percent for FY 2019/20. Without the emergency response package, annual growth for FY 2019/20 may have been as low as 1.9 percent.

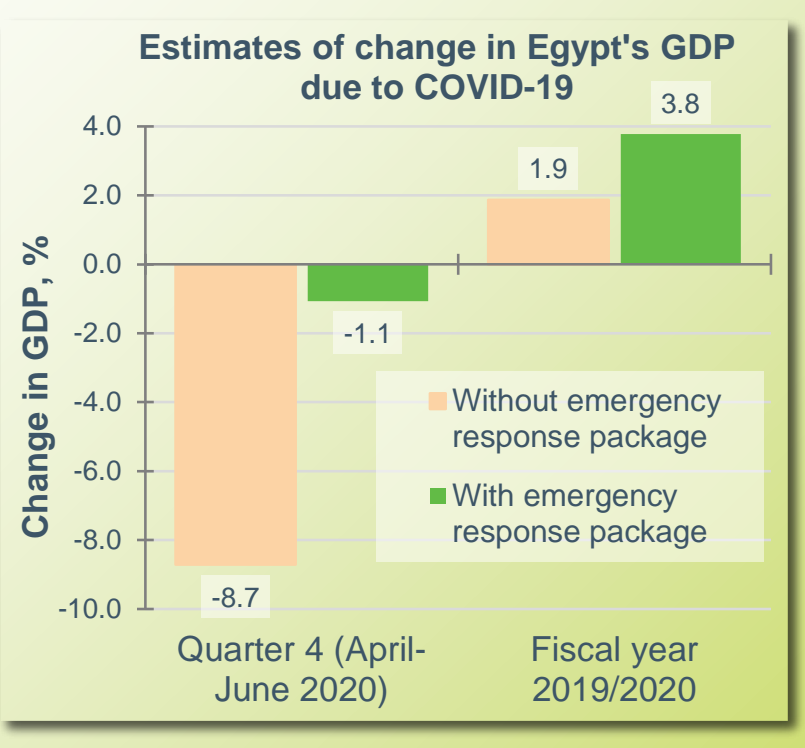

The services sector is hit hardest, falling by 10.9 percent, followed by industry at -8.3 percent. Agriculture is the most resilient sector. However, these losses are lower than those expected in comparable countries, especially those that resorted to extended periods of full lockdowns. Impacts on Egypt's agri-food system are less severe than elsewhere in the economy. Most damage will occur in nonfarm components of the agri-food system due to falling consumer demand.

Although higher-income households face the largest income losses, lower-income households also will see their incomes decline significantly. The level of social protection required to fully offset the income losses of poor households is likely to be prohibitive, especially given falling revenues from reduced economic activity.

Continuing to gradually open the economy again will be critical for avoiding permanent job losses and increases in poverty for the coming year. The process of re-opening the economy may also provide opportunities for fostering more private sector-driven and sustainable economic transformation. 


\section{COVID-19 is interrupting Egypt's economic success story}

As the COVID-19 crisis continues, the global economy is witnessing the worst economic crisis since the Great Depression of the 1930s. The International Monetary Fund predicts that all countries will experience a slowdown in their economic activity. COVID-19 is also interrupting Egypt's recent economic success. The impacts of the global COVID-19 crisis are increasingly and directly affecting the local economy. The number of infected cases with COVID-19 is low by international standards. However, the number has increased in Egypt over the past few weeks. As of 14 June 2020, total cases had risen to 44,598, while the death toll stood at 1,575, according to the Ministry of Health.

Egypt reacted relatively early to curb the outbreak of this pandemic. Around mid-March, the government implemented many measures to contain the spread of COVID-19, including travel bans on international commercial passenger flights, a nighttime curfew from $8 \mathrm{pm}$ to $6 \mathrm{am}$, bans on gatherings, and the closure of schools and religious institutions (Figure 1). While many factories remain open, working hours and work shifts are often reduced. These domestic anti-COVID-19 measures are modest by international standards as the partial lockdown of the Egyptian economy aims to strike a balance between public health and economic considerations. Hence, the country has managed to operate under a slower pace of economic activity, but has avoided a full lockdown. ${ }^{1}$

Nevertheless, negative external factors combined with the partial lockdown are expected to cause significant disruptions to the strong economic progress that Egypt has achieved during the past year. To counter these adverse effects, the government acted to support economic activities and households via accommodating fiscal and monetary policies. These include allocating 100 billion Egyptian Pounds (EGP) to combat some of the economic fallout from COVID-19, cutting interest rates, providing loans with reduced interest rates to support the hardest hit sectors, and expanding social safety nets (Figure 1).

However, the partial lockdown of the economy combined with unfavorable external conditions reduces economic activity. To estimate the combined impacts of COVID-19 from shocks, such as the reductions in revenue from tourism and a sharp drop in payments received from the Suez Canal, together with the domestic precautionary measures that have been put in place, we adapt an expanded version of the Social Accounting Matrix (SAM)-based multiplier model for Egypt (Thurlow 2020).

The remainder of this policy note is organized as follows. The next section highlights the main domestic impact channels through which the COVID-19 crisis is expected to affect the performance of the Egyptian economy as a whole. We then describe the main features of the methodology used to assess the impact of the COVID-19, i.e., the SAM multiplier model. Thereafter, the model results are reviewed with regards to changes in GDP, employment, and household incomes. The final section maps some of the key elements for the pathway back to strong economic growth in Egypt.

\section{COVID-19 impacts differs across sectors - most lose, some benefit}

To determine the combined impact of COVID-19 on the Egyptian economy between April and June 2020, we build a sector-by-sector assessment of the economic impact of COVID-19 that draws on various sources, including Egyptian Center for Economic Studies (ECES), the Ministry of Planning and Economic Development (MPED), various news sources, and expert opinions. We summarize here our assessment for the main sectors of the Egyptian economy and specify in Table 1 our assumptions on the size of the economic shock by sub-sector. These assumptions on the size of the shock on the specific sub-sectors are used in our SAM multiplier model scenarios.

\footnotetext{
${ }^{1}$ Encouraged by the relatively low rate of infections compared to population size.
} 
Figure 1: Egypt - timeline of new COVID-19 cases and policy responses, mid-February to early-June 2020

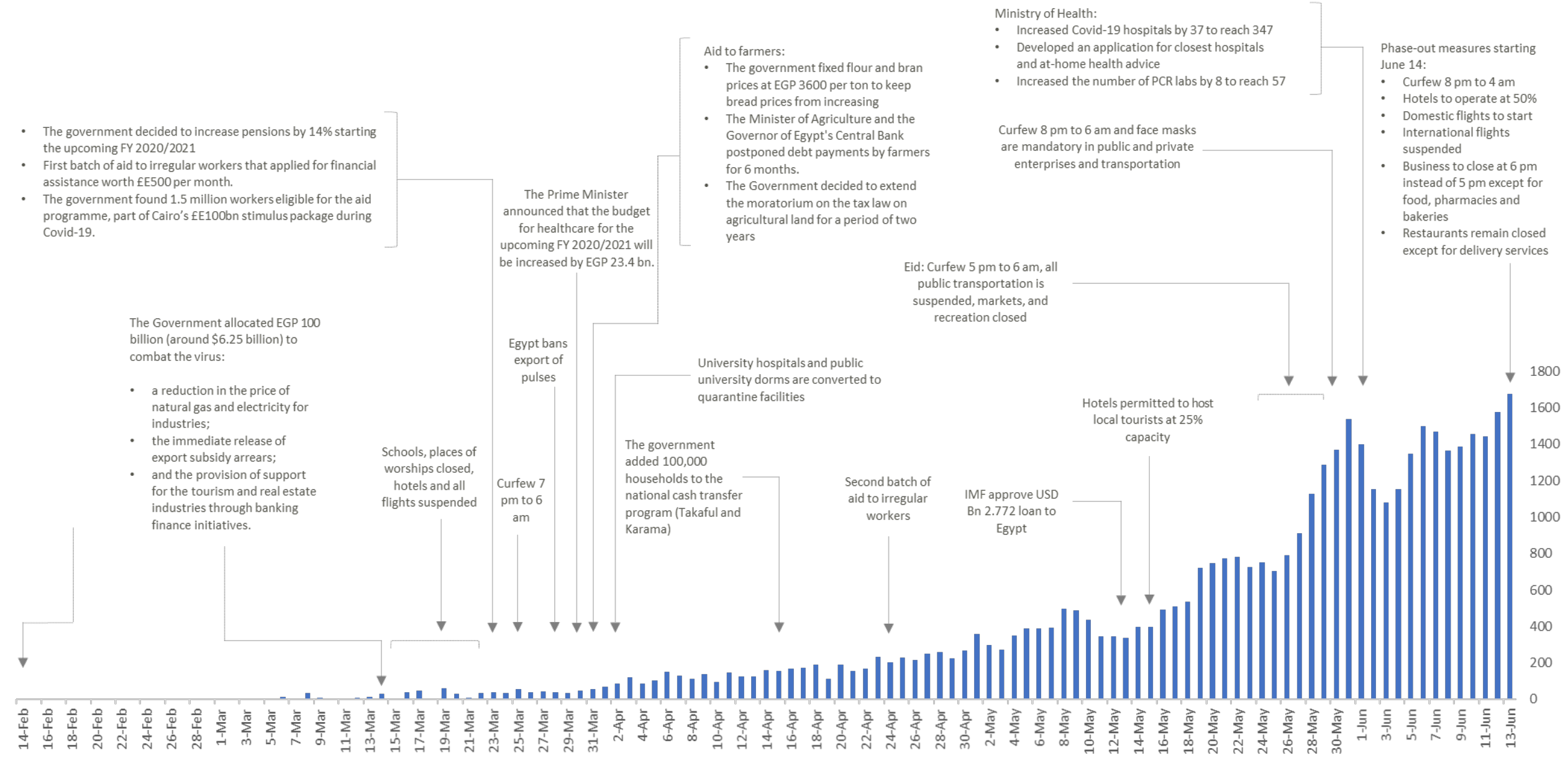

Source: IFPRI Food Policy Response Monitor. 
Agriculture: Domestic agricultural production plays a key role for food security, especially during times of international crises. Maintaining or even expanding agricultural production during the COVID-19 crisis is a high priority for all governments around the world. Therefore, there are usually no explicit restrictions for farmers, traders, and food markets.

However, seasonality plays a key role for agricultural production. In Egypt, important staple crops, such as wheat and rice, are already planted and will be harvested in coming weeks. Fruits, vegetables, and livestock are produced throughout the year, with most destined for the domestic market. Therefore, in over the next three months we assume that the COVID-19 pandemic will have no direct impact on most agricultural crop production, except for wheat, the output of which is likely to grow due to higher procurement prices. We also assume an increase by 10 percent in livestock production, as many livestock farms have been encouraged to produce additional meat and dairy products in order to substitute for a possible decline in imported livestock products. Our model also captures the potential indirect impact on agriculture that is likely to arise from reduced demand for food from hotels and restaurants.

Industry: The industrial sector is diverse. Its sub-sectors are likely to be affected differently:

- Food processing: Food products are considered essential consumer products and production in Egypt relies mainly on locally produced agricultural inputs. Recent news reports state that food products have seen an increase in demand over recent weeks and that local processing has been increasing to substitute for the decline in imports of processed food items as well as to accommodate the high demand for food products during the holy month of Ramadan, which occurred in May. Therefore, we assume that the food processing sub-sector will see an increase of 10 percent as a result of the COVID-19 crisis.

- Textiles and clothing: Due to the significant drop in domestic and foreign demand, many factories have stopped production; others are utilizing only 50 percent of their productive capacity. Apparel exports, which represent 44 percent of the sub-sector's total output, are likely to decrease due to a decline in global orders (ECES 2020). On the supply side, as the industry depends on imported raw materials from China and India, the sector is also expected to suffer from disruptions in global supply chains, e.g., China is the source of 50 percent of Egyptian imports of textiles and yarn. Taken together, we expect a 30 percent decline in the productive capacity of this sector.

- Chemical and pharmaceutical products: The nature of this health crisis leads to higher demand for medical supplies, sanitizers, and related products of chemical industries. We assume that COVID-19 will lead to a 30 percent increase in demand for such products.

- Durables and consumer goods, such as metals and machinery: We expect to witness a significant decline in output of such goods. The reason is a combination of reduced demand and bottlenecks in the supply of intermediate inputs. We assume a 20 percent decline in metals and machinery and a 20 percent decline in other manufacturing activities. 
- Construction: As the construction sector is a large sector and important for providing jobs, construction activities continue in many places as the government balances the need to keep projects running while implementing precautionary measures, such as social distancing and lower numbers of workers on construction sites. Relative to many manufacturing sub-sectors, we assume a smaller decrease in construction activity of 5 percent.

\section{Services:}

- Information and communication technologies: Home office, e-learning, online shopping, and other internet-based activities have led to a sharp rise in the use of internet and other information sector related services. The Minister of ICT, for example, recently announced that the consumption of internet services increased by around 50 percent.

- Transportation: Air traffic has dramatically decreased and is mainly limited to freight. Home office work and the partial curfew has reduced the demand for land transportation, including taxis, ride-hailing companies, buses, and metro. We assume air transport will be reduced by 90 percent and land transport by 30 percent.

- Trade, wholesale and retail: Partial closure of trading establishment during the curfew reduces their productivity. Thousands of businesses, including coffee shops and commercial outlets, have had to close. To reflect these restrictions on trading, we assume a 15 percent decline in the wholesale and retail trade sectors.

- Hotels and food services: In March 2020, tourism in Egypt had started to decline - between 70 and 80 percent of future bookings were cancelled. With the banning of international flights across most countries of the world, a complete loss in international tourism revenues is likely to occur for the next few months and potentially until the end of the year (ECES 2020). Based on the estimate that internal tourism accounts for 10 percent of total hotel occupancy, we assume a decline of 90 percent for the total tourism sector.

- Other services, including entertainment, recreation, cultural, and sports activities: The government has banned all large public gatherings, including cultural events and conferences, and closed venues, such as cinemas, popular markets, gyms, and parks. All team sports activities have been halted, and all sporting clubs and youth centers are closed until further notice. We assume a decline by 20 percent in sports and recreational activities.

- Public services: Due to this unprecedented health crisis, we assume increasing demand for the provision of health services. The government has allocated more funds to support the health system via the importation and production of test kits, drugs, ventilators, and other medical supplies. Moreover, the government has approved a 75 percent increase to the salaries of health workers in addition to giving them a one-time allowance. Hence, we assume an increase in the output of health services of 35 percent. Combining this with the assumption of unchanged output for other public services (like schools), we assume an increase in public services of 3.6 percent.

\section{Assessing short-term COVID-19 impacts with a SAM multiplier model}

Social Accounting Matrix (SAM) multiplier models are ideally suited to measuring short-term direct and indirect impacts of unanticipated, rapid-onset demand-side economic shocks, such as those caused by the COVID-19 pandemic. At the heart of the multiplier model is a SAM, an economywide database that captures resource flows associated with all economic transactions that take place in the economy, usually over the course of a financial year. As such, the SAM represents the structure of the economy, showing the relationships between actors, i.e., productive activities, households, government, and external sector, in terms of how they interact and transact via commodity and factor 
markets. The SAM multiplier model provides a mechanism for estimating the effects of an external shock - typically an exogenous change in final demand for goods and services - on sectoral and national production, factor incomes (wages or rents), and household incomes on the basis of the production, employment, and consumption relationships captured in the SAM.

Apart from the direct production effect in the sector affected by the demand change, other sectors are affected indirectly via changes in demand for intermediate inputs. Additionally, resulting changes in the levels or composition of employment could lead to further changes in household consumption demand. The strength of the multiplier model lies in the fact that the multiple rounds of these indirect effects are fully captured. The more detailed the SAM is in terms of the activities, commodities, and factor and household accounts it includes, the more refined the SAM multiplier analysis is in terms of analyzing the direct and indirect impact pathways and distributional effects of the external shock.

Since this is a short-run analysis period, it is assumed that technical input-output relationships, the input choices of producers, and the consumption patterns of households do not (as yet) change in response to the simulated shock. Such behavioral responses are captured in general equilibrium models, but the anticipated short-term nature of the COVID-19 shock and the likelihood that the economy will return to a "business-as-usual" state once the crisis dissipates over time makes the SAM multiplier framework a more appropriate tool for analyzing this particular shock. (Breisinger et al. 2009; Round 2003.). Consistent with the short-term nature of the analysis, we assume that net expenditures for households and government, patterns of savings and investment, and international trade are exogenous to the model. i.e., we do not take into account second-round effects on these economic flows.

The Egypt multiplier model is based on a SAM developed jointly by Egypt's Central Agency for Public Mobilization and Statistics (CAPMAS) and the International Food Policy Research Institute (IFPRI). While the SAM itself has a 2015 base-year, multiplier results are applied to national accounts, household income, and population data for 2019 to permit an assessment of the likely impacts of COVID-19 in 2020. This note uses an extended version of the multiplier model that captures sector-level impacts and seasonality in the impacts (Thurlow 2020). Figure 2 summarizes the underlying conceptual framework of the Egypt SAM multiplier model.

\section{Figure 2: Conceptual framework of the SAM multiplier model for the Egyptian economy}
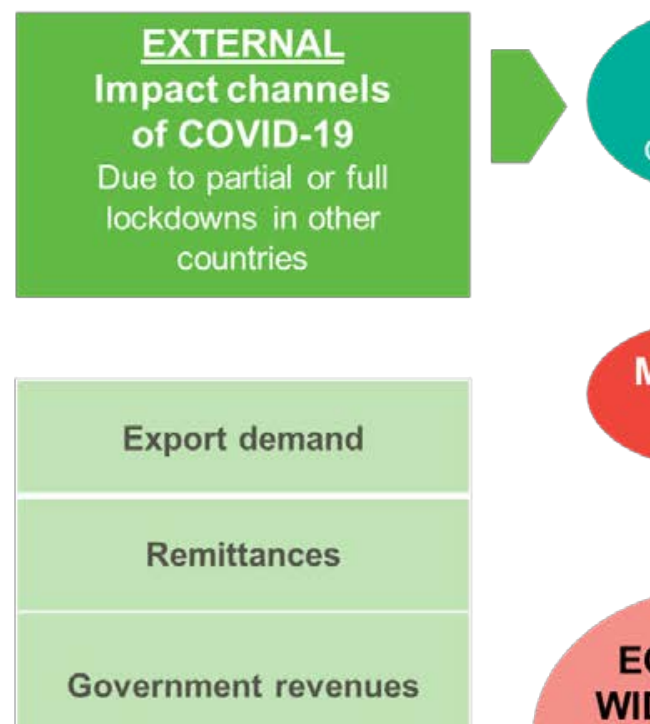

Direct

impact

channels

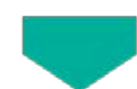

Multiplier impact

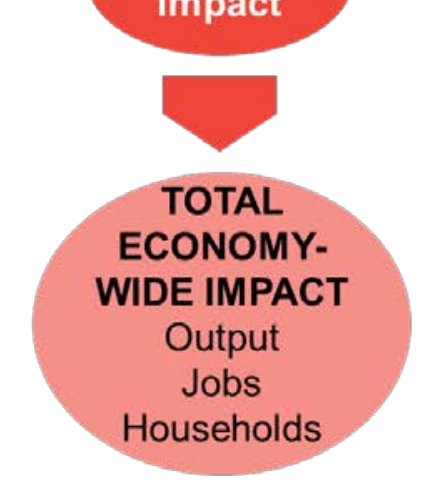

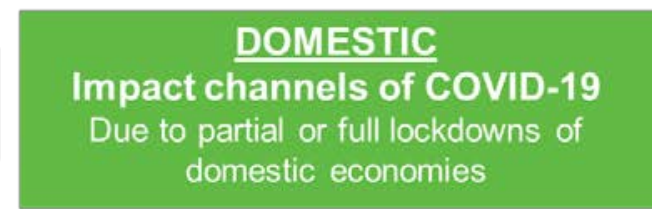

Agriculture Banking, finance \& insurance

Mining \& crude oil Professional \& business services

Manufacturing Public admin \& law enforcement

Utilities

Education services

Construction Health services

Wholesale \& retail Sports \&

trade services entertainment

Transportation,

storage \& cargo

Other services

Hotels \& food

services 
There are external and internal (domestic) impact channels. External channels include exports and remittances, while the domestic impact channels depend on full or partial lockdown measures. These domestic impact channels might provoke negative effects, such as the closure of restaurants, factories, and commercial shopping centers. They also might induce positive outcomes. especially with regards to the communication and the health-related sectors. In the SAM multiplier model, a closure of restaurants, for example, is modeled as a 100 percent loss of restaurants output. Similarly, if textile factories are operating with two shifts instead of three, we assume a reduction of about 30 percent in the output of the textile sub-sector.

Both the external and domestic impact channels induce a direct impact on economic activity. However, there are also several rounds of indirect effects. For instance, the closure of restaurants and hotels would result in sharply reduced demand for food commodities. These are the multiplier effects that are captured by our economy-wide SAM multiplier model.

We also account for the government of Egypt's emergency response package of EGP 100 billion to combat the COVID-19 pandemic. The impacts of the package are partly captured in the assumptions about sector-level impacts as part of the multiplier model and, as such, reflect the package's impact on the health sector and other sectors. Parts of the package go to subsidized loans, to stimulate the Egyptian stock market, and to other measures to support economic activity. As such measures cannot easily be captured in the multiplier model framework but likely do contribute to economic growth, we conduct a separate calculation based on the assumption that the EGP 100 billion will directly support GDP in Q4. ${ }^{2}$

\section{COVID-19 significantly reduces economic output in Q4, but overall growth in FY 2019/20 will remain positive}

We estimate that quarterly GDP for April to June 2020 may have shrunk by -8.7 (at market prices) if the government did not put an emergency package in place (Figure 3). The estimate of a drop in GDP of 8.7 percent is small by international standards and is due to the government having avoided a full lockdown. Assuming that the whole emergency response package is implemented during April and June and directly contributes to economic growth, we estimate a loss of -1.1 percent of GDP compared to the same quarter in the previous year. Combining this assumption with preliminary estimates by MPED for quarters 1 to 3, we estimate an annual growth rate for the FY $2019 / 20$ of 3.8 percent (Appendix 1). Without the emergency response package, annual growth for FY 2019/20 may have been as low as 1.9 percent.

Relative to a situation without the pandemic, COVID-19 is projected to substantially reduce economic output in most sectors. Our results document a sizable adverse impact on economic output and household welfare in Egypt, but much will depend on how long the COVID-19 crisis will persist.

GDP losses emanate from the drop in the services and industry sectors, which are expected to contract by 10.9 percent and 8.9 percent respectively (Figure 4). The expected loss in overall GDP would have been

Figure 3: Estimates of change in Egypt's GDP due to COVID-19

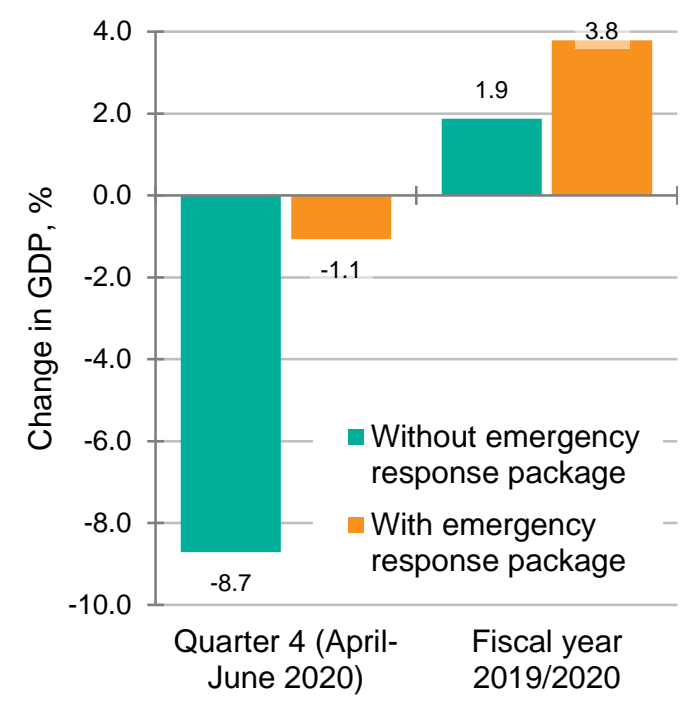

Source: COVID-19 Egypt multiplier model.

Note: See Appendix 1 for detailed calculation.

\footnotetext{
${ }^{2}$ For an overview of policy responses, see MPED's policy tracker https://mped.gov.eg/policytracker/dist-2/index.html
} 
greater without anticipated positive growth in the agriculture sector amounting to 2.3 percent.

The loss of GDP in the services sector is dominated by the partial closing of trade activities and the reduction of air and land transport, both of which have a significant impact on GDP (Figure 5). The reduction of industrial and manufacturing activities is due to both significant direct and indirect effects. Almost all the sectors were affected negatively by the partial lockdown. Moreover, direct impacts are magnified by indirect effects that are induced by changes in the demand for intermediate inputs or strong forward linkages, especially for food processing, trade, and transportation.

Impacts on food systems are also substantial, although less severe than elsewhere in the economy. The loss in the agri-food system amounts to around EGP 9.6 billion. Most of this economic damage occurs
Figure 4: Estimates of change in sectoral GDP for Egypt due to COVID-19, 4th quarter, FY 2019/20

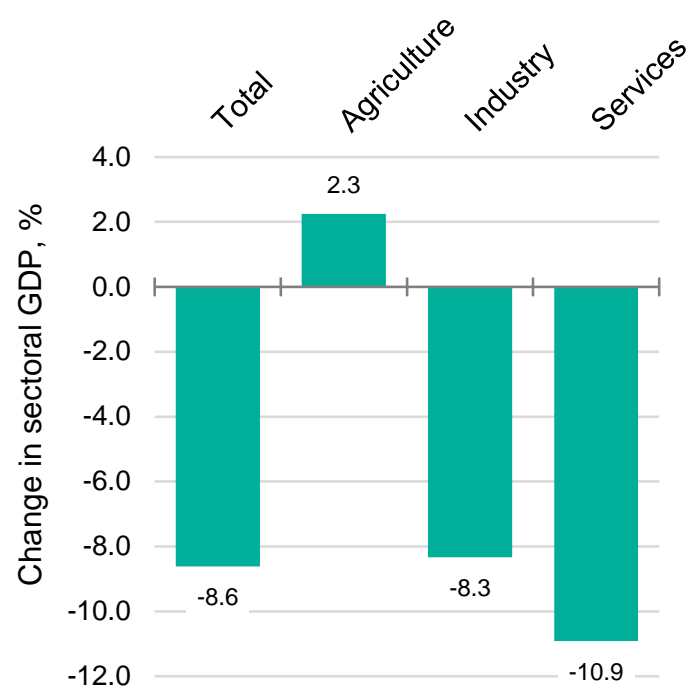

Source: COVID-19 Egypt multiplier model. in food services (including hotels and restaurants), with an estimated loss of 59.5 percent (Figure 6). Agriculture is the most resilient component of Egypt's agri-food system with an expected increase in output of around EGP 3 billion. This is driven chiefly by increased livestock production. Losses in food processing also are relatively small and also are driven by indirect effects, such as, for example, restaurants and hotels demanding less food. Some food processors may even benefit from the COVID-19 crisis if they are able to engage in production of previously imported processed foods.

Figure 5: COVID-19 final estimated impacts on sub-sector production in Egypt, $4^{\text {th }}$ quarter, FY 2019/20

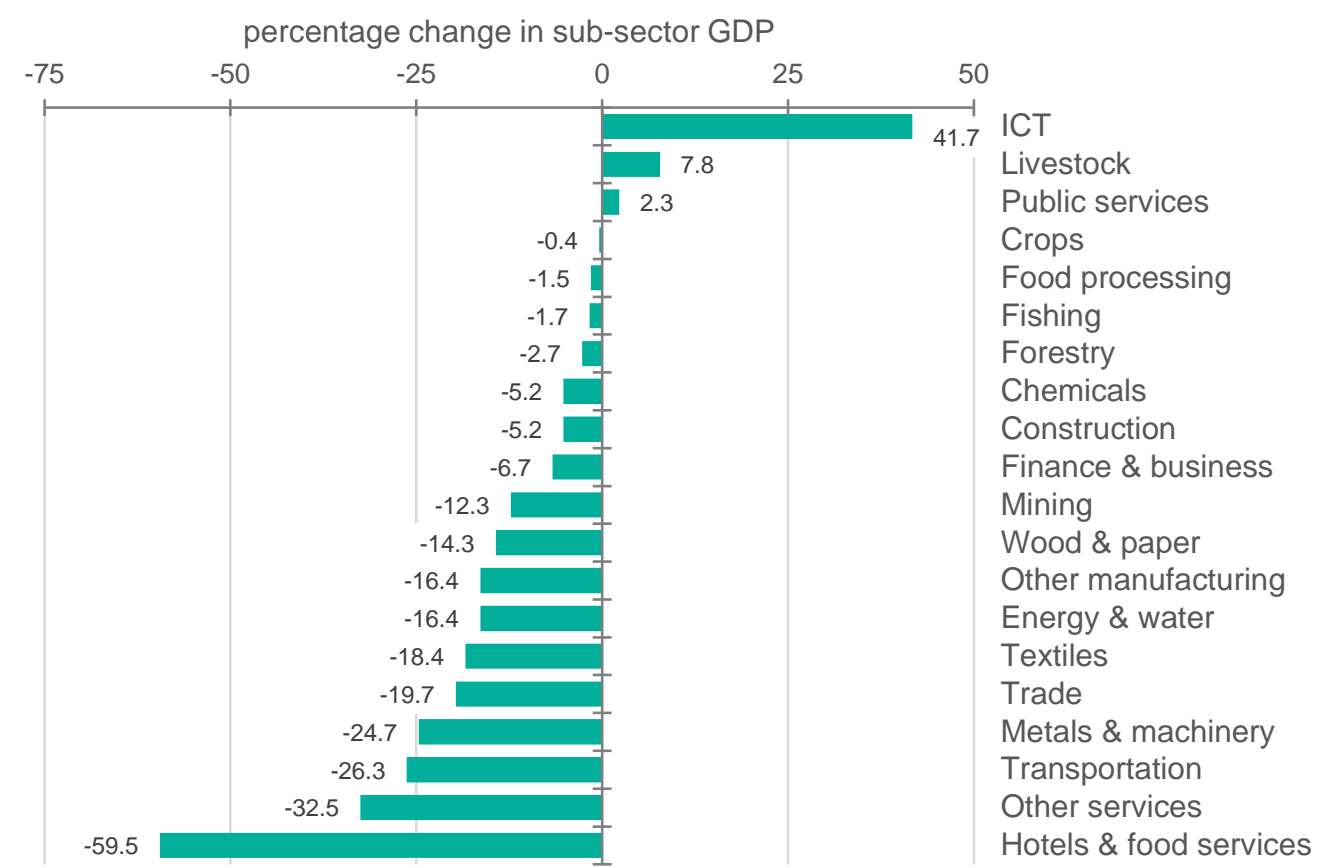

Source: COVID-19 Egypt multiplier model.

Note: Fourth quarter (April to June) of 2019/20 fiscal year. ICT = Information and Communication Technologies 
Figure 6: COVID-19 impacts on Egypt's agri-food system, $4^{\text {th }}$ quarter, FY 2019/20
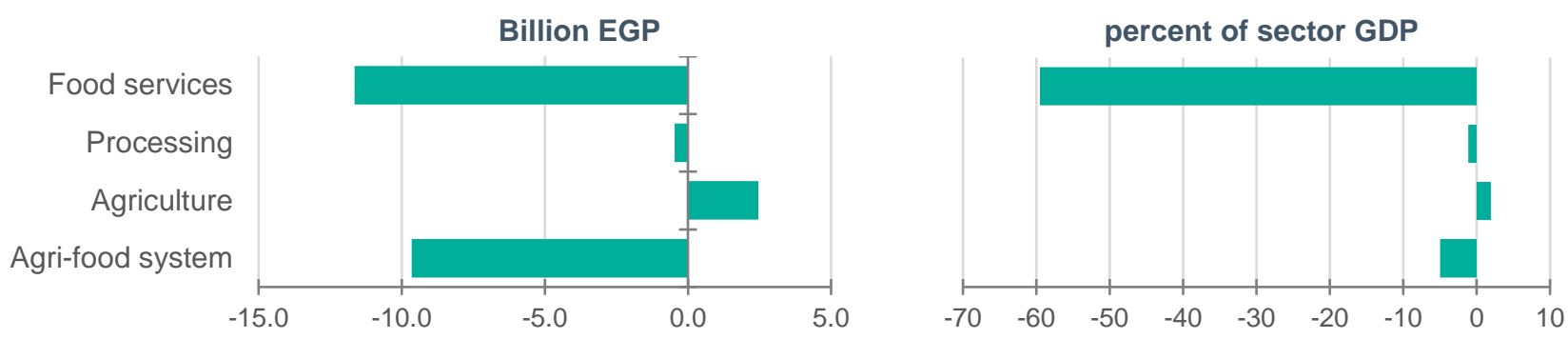

Source: COVID-19 Egypt multiplier model.

Note: Fourth quarter (April to June) of 2019/20 fiscal year.

This COVID-19 induced reduction in economic output may translate into temporary job losses of 600,600 jobs between April and June 2020, especially in services and industry. The job losses are mainly driven by the impact of COVID-19 on the deployed work force in services, followed by industry (Table 2). A small number of new job opportunities are seen in agriculture. This increase stems from labor moving from urban to rural areas. Job losses are strongest in those sectors that are most heavily affected by the supply and demand shocks following COVID-19, i.e., hotels and restaurants, sports and recreational activities, household workers, and industry.

Table 2: COVID-19 impact on employment in Egypt by economic sector, by length of economic slowdown, thousands of workers

\begin{tabular}{lcccc}
\multicolumn{1}{c}{ Period } & Total & Agriculture & Industry & Services \\
One month & -200.2 & 4.4 & -52.9 & -151.7 \\
Two months & -400.4 & 8.9 & -105.8 & -303.5 \\
Three months & -600.6 & 13.3 & -158.7 & -455.2 \\
\hline
\end{tabular}

Source: COVID-19 Egypt multiplier model.

Better-off, urban households tend to be harder hit, but the poor may find it harder to cope. Average household income is estimated to decline by EGP 405 (or 7.5 percent) per household per month between April and June 2020 (Figure 7). The expected reduction in service sector activities has the strongest effect on all households. These reductions are especially driven by reductions in trade, transport, retail, hotel, and sport services. Households are also affected by the slowdown in manufacturing activity and by lower remittances from abroad.

While all households are hurt by lower economic activities, it is urban households that are most affected by the COVID-19 crisis. The urban nonpoor households suffer the most from the economic impacts of COVID 19 in absolute terms with an average monthly income reduction of 740 EGP (or -8.8 percent of income). The urban poor are estimated to lose 271 EGP (or -9.7 percent of income). These urban households receive most of their income from employment in the services and

Figure 7: COVID-19 impacts on total household monthly income, 4th quarter, FY 2019/20

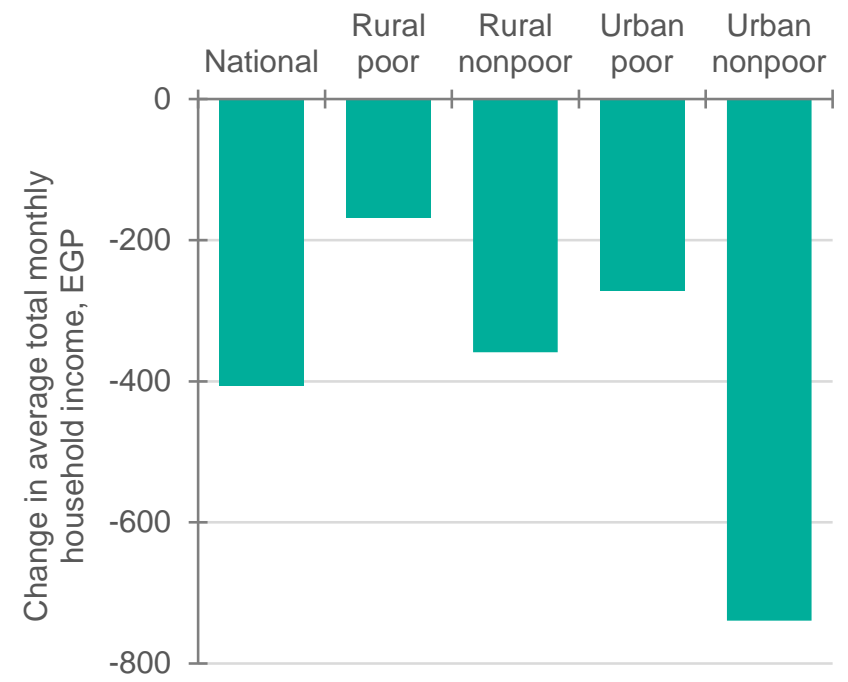

Source: COVID-19 Egypt multiplier model.

Note: Fourth quarter (April to June) of 2019/20 fiscal year

Poor= lower two income quintiles. Nonpoor=upper three income quintiles. 
industrial sectors, which are the sectors of the Egyptian economy most hit by the closing of businesses and lower tourist expenditures. In addition, income losses of non-poor urban households are driven by large shares of income coming from self-employment and from profits in industry and services; the sectors most affected by the crisis.

Rural households also lose, but less than their urban counterparts. The rural nonpoor see reductions in their incomes of 359 EGP (or 6.1 percent of income) and the rural poor households see a reduction in their monthly income by 168 EGP (or -6.2 percent of income) (Figure 7). The relatively lower losses of rural households can be explained by the growth expected in the agricultural sector. While the income losses of the rural and urban poor are smaller compared to the nonpoor in absolute terms, poor households are likely to find it harder than wealthier households to cope with such income losses.

\section{Towards a new normal - gradual reopening and new opportunities}

By implementing a partial lockdown, Egypt has managed to operate under a slower pace of economic activity, but has avoided a full lockdown. Unavoidably, the combination of external shocks caused by lockdowns in other countries and the partial lockdown domestically leads to a significant contraction of economic output. Taking the emergency package into account we estimate a reduction in quarterly GDP of -1.1 percent between April and June 2020. Services are hit especially hard, followed by industry. With regards to Egypt's agri-food system, we estimate significant losses, although less severe than elsewhere in the economy. Most economic damages occur in the nonfarm components of the agri-food system and mainly result from falling consumer demand.

The reduction in the economic activity translates into a temporary loss in employment levels of around 600,000 jobs. This will induce an adverse effect on the household income. Higher-income and urban households face the largest income losses, as they receive most of their income from employment in the services and industrial sectors that are most hit. Lower-income and rural households also see their incomes declines significantly and will find it more difficult to cope. In this regards, the government has taken bold actions to support these vulnerable groups, by allocating a monthly allowance of EGP 500 for seasonal workers who lost their jobs and by increasing the number of beneficiaries under the Takaful and Karama social protection programs. However, the level of social protection required to fully offset poor households' income losses is likely to be prohibitive, especially given falling revenues from reduced economic activity and constraints on foreign borrowing.

Therefore, gradually continuing to fully open the economy again will be critical for avoiding permanent job losses and increases in poverty. Hotels, restaurants, sport and leisure facilities, retail, and manufacturing are important sectors to start with. The re-opening of the economy and related government support to sectors may also provide opportunities for fostering sustainable economic transformation. For example, limited opportunities to import goods during the crisis may provide an opportunity for Egyptian companies with a comparative advantage such as labor intensive manufacturing to start producing more of these goods domestically. In addition, government support to certain sectors may be geared towards sectors that can foster sustainable transformation and create jobs. For example, supporting the ITC sector will help foster digitization of government and business services, e-learning, and remote online work.

For the post-COVID-19 recovery and transformation to be successful and sustainable, the government should work closely with the private sector, improve the business climate, and continue undertaking serious reforms to overcome institutional weaknesses. 


\begin{tabular}{|c|c|c|}
\hline & $\begin{array}{c}\text { GDP } \\
\text { change, } \%\end{array}$ & Source \\
\hline \multicolumn{3}{|l|}{ Annual FY 2019/20 } \\
\hline Without intervention by government of Egypt & 1.9 & Combined estimate \\
\hline With intervention by government of Egypt & 3.8 & Combined estimate \\
\hline \multicolumn{3}{|l|}{ GDP (by fiscal year quarter) } \\
\hline Q1 (July to September 2019) & 5.6 & MPED \\
\hline Q2 (October to December 2019) & 5.6 & MPED \\
\hline Q3 (January to March 2020) & 5.0 & MPED \\
\hline Q4 (April to June 2020) & & IFPRI multiplier model \\
\hline Without intervention & -8.7 & Calculated \\
\hline With intervention & -1.1 & Calculated \\
\hline \multicolumn{3}{|c|}{ Components of Q4 change in GDP without government intervention } \\
\hline At factor cost & -8.6 & IFPRI model \\
\hline Net indirect taxes & -0.1 & MPED \\
\hline At market price & -8.7 & \\
\hline \multicolumn{3}{|c|}{ Components of Q4 change in GDP with government intervention } \\
\hline Stimulus (billion EGP) & 100 & Government of Egypt \\
\hline Q4 GDP (billion EGP) & 1,308 & \\
\hline Change in Q4 GDP due to stimulus (\%) & 7.6 & \\
\hline $\begin{array}{l}\text { Combined with Q4 GDP estimate for without } \\
\text { intervention }(-8.7 \%)\end{array}$ & -1.1 & \\
\hline
\end{tabular}

Source: Compiled by authors.

Note: These are based on estimates for quarters 1 to 3 of FY 2019/20 by the Ministry of Planning and Economic Development (MPED) and the IFPRI multiplier model for quarter 4. Egypt's fiscal year (FY) runs from July to June. Annualized changes are with reference to respective time period in FY 2018/19.

\section{References}

Breisinger, C., A. Abdelatif, M. Raouf, and M. Wiebelt. 2020. COVID-19 and the Egyptian economy: Estimating the impacts of expected reductions in tourism, Suez Canal revenues, and remittances. MENA Regional Program Policy Note 04. Cairo: International Food Policy Research Institute.

Breisinger, C., M. Thomas, and J. Thurlow. 2009. Social accounting matrices and multiplier analysis. An introduction with exercises. Washington, DC: International Food Policy Research Institute.

ECES (Egyptian Center for Economic Studies). 2020. "Views on Crisis. Industries struggling to survive: Clothing and Apparel." Views on News. Issue 11. Cairo: ECES. http://www.eces.org.eg/cms/NewsUploads/Pdf/2020_4_3012_40_3830-4-2020-\%20English-\%20DR.Rama\%20.pdf

MPED (Ministry of Planning and Economic Development ). 2020. Policy Interventions to mitigate the adverse impacts of Covid19 on the Egyptian Economy. Unpublished working paper. Cairo: MPED

Round, J. 2003. "Social Accounting Matrices and SAM-based Multiplier Analysis." In F. Bourguignon and L. A. Pereira da Silva, eds. Techniques and Tools for Evaluating the Poverty Impact of Economic Policies. Washington, DC and Oxford, UK: World Bank and Oxford University Press. ch. 14.

Thurlow, J. 2020. A standard multiplier model for COVID-19 assessments. Unpublished SAM multiplier model (available upon request). Washington, DC: International Food Policy Research Institute. 


\section{ABOUT THE AUTHORS}

Clemens Breisinger is a Senior Research Fellow in the Development Strategy and Governance Division (DSGD) of the International Food Policy Research Institute (IFPRI) and Head of IFPRI's Egypt Strategy Support Program (ESSP), based in Cairo. Mariam Raouf is a Senior Research Associate of ESSP, based in Cairo. Manfred Wiebelt is a Senior Research Fellow and Professor of Economics at the Kiel Institute for the World Economy, Kiel, Germany. Ahmed Kamaly is Deputy Minister, Ministry of Planning and Economic Development of the Government of the Arab Republic of Egypt, based in Cairo. Mouchera Karara is Associate Minister for Economic Policies in the Ministry of Planning and Economic Development, based in Cairo.

\section{ACKNOWLEDGMENTS}

We thank Her Excellency, the Minister of Planning and Economic Development Prof. Dr. Hala El Said for her support and comments. We also thank Dr. Abla Abdel Atif, Executive Director; Dr. Diaa Noureldin, Senior Advisor; Dr. Sahar Aboud, Principal Economist; Racha Seif Eldin, Senior Economist; and Mohamed Hosny, Economist, all at the Egyptian Center for Economic Studies (ECES), for their inputs to this study through their excellent work on ECES's Views on News - Views on Crisis series. We also are grateful to James Thurlow for developing the extended prototype COVID-19 multiplier model template in Excel; to Dalia Elsabbagh and Hosam Ibrahim, both of IFPRI, for excellent research assistance; and to Fadi Abdelradi of Cairo University for his useful inputs and comments.

We also gratefully acknowledge the financial support of the United States Agency for International Development (USAID), which made this study possible under the project "Evaluating Impact and Building Capacity" (EIBC) that is implemented by IFPRI. We are particularly grateful for the support of Ayat El- Dersh, Project Management Specialist (M\&E), and Michael Trueblood, Deputy Director, both of the Office of Economic Growth, USAID/Egypt.

The information provided in this paper is not official U.S. government information and does not represent the views or positions of the United States Agency for International Development or the U.S. Government. Any opinions stated herein are those of the authors and are not necessarily representative of or endorsed by IFPRI and the Ministry of Planning and Economic Development. 